\title{
Firm and whole chain success: network management in the Ukrainian food
} \section{industry}

\author{
T. Gagalyuk ${ }^{1}$, J.H. Hanf ${ }^{2}$ and M. Hingley ${ }^{3}$ \\ ${ }_{1}^{1}$ Association Ukrainian Agribusiness Club, Velyka Zhytomyrska Str. 20A, 01001 Kiev, Ukraine \\ ${ }^{2}$ Geisenheim University, Von-Lade-Str. 1, 65366 Geisenheim, Germany \\ ${ }^{3}$ University of Lincoln, Brayford Pool,LN6 7TS, Lincoln, United Kingdom; mhingley@lincoln.ac.uk
}

\section{RESEARCH ARTICLE}

\begin{abstract}
This article develops the theoretical foundations of supply chain network management in order to investigate the constructs surrounding whole chain success rather than just success at firm level. It is argued that the 'network success' link has been under-studied, with most empirical studies focusing on the achievement of goals by an individual firm in a network context. A model of the whole network's success in the context of supply chain networks in food industry supply chain relationships is used. The results identify that network-level goals must be considered alongside firm-level goals in supply chain networks. Furthermore, network-level goals are subject to the impacts of chain management and have to be of particular interest for focal firms that are responsible for the development and implementation of collective strategies.
\end{abstract}

Keywords: integrated channel relationships, food

\section{Introduction}

As suggested by the proponents of the relational view of strategic management, the advantages of an individual firm are often linked to the advantages of the network of relationships in which the firm is embedded (Dyer and Singh, 1998). Accordingly, there is an ongoing discussion on how to manage a firm's network of relationships successfully, i.e. such that the firm's competitive advantage is sustained (Dyer and Hatch, 2006; Gulati et al., 2000; Kale et al., 2002).

It seems, however, that the discussion about network management has not exhaustively addressed the 'network management - network success - firm success' causeand-effect chain. Given that success generally means the achievement of goals, we argue that the 'network success' link has been under-studied, in particular, because of incomplete interpretation of network goals. In fact, most empirical studies that declare their focus on the network success or performance address the achievement of goals by an individual firm participating in a network and analyse the role of network-related 'collective constructs' such as inter-firm trust, commitment and relational norms (Medlin, 2006: 860) in achieving those goals. Yet, goals that are set at the network level, i.e. collectively pursued outcomes, are mainly neglected although their presence and relevance in inter-organisational relationships has been widely emphasised (e.g. Pitsis et al., 2004; Van de Ven, 1976; Winkler, 2006) ${ }^{1}$.

As shown by Medlin (2006), collective constructs need to be studied in the context of both collective and self-interest outcomes. Focussing solely on the goals of an individual firm in a network will provide biased results with respect to management styles that are actually based around self and collective interests, i.e. around the whole network of relationships. Thus, without simultaneous consideration of goals at the firm and network levels and without an understanding of how the network should be managed in this respect, the whole network's success will remain under-

\footnotetext{
${ }^{1}$ Empirical investigations of the achievement of collective goals have been undertaken in the context of dyads, e.g. in strategic alliances (Ariño, 2003; Schreiner et al., 2009), strategic partnerships (Mohr and Spekman, 1994) and dyadic supply chain relationships (Paulraj and Chen, 2005). Provan and Milward (1995) have considered network-level goals in their study of network effectiveness in public sector. Gellynck et al. (2008) measured supply chain performance in the traditional food sector as the level of achievement of goals common to all the supply chain parties. However, to the best of our knowledge, empirical analysis of collective goal achievement at the network level has not been yet carried out in the strategic management context. Neither has it combined the achievement of network-level goals with the achievement of firm-level goals.
} 
defined and the validity of the derived implications will be challenged.

Therefore, the aim of this study is to develop and test the model that includes the relationships between goal achievement at the firm and network levels, and the theoretical constructs that are conceptualised as the determinants of goal achievement. We test our model of the whole network's success in the context of supply chain networks in the food industry. In particular, our study examines the relationships (1) between a food manufacturer and its independent (upstream) suppliers and (2) between the food manufacturer and its independent (downstream) customers.

The article proceeds as follows. First, we delineate the theoretical foundations of supply chain network management. In this part, we build on prior research on management of procurement relationships to generate hypotheses that constitute our conceptual model. Next, we test the model and discuss the results. Finally, we derive some implications.

\section{Theory and hypotheses}

As maintained by the representatives of the Centre for Research in Strategic Purchasing and Supply (Christopher, 1992; Harland et al., 2001; Lamming et al., 2000), the concept of supply chain networks encompasses a more manageable set of issues compared to the broad concept of unmanageable networks defined by the IMP Group (Ford, 1990; Håkansson and Snehota, 1995). This involves the tasks performed in supply chains to serve end-customer segments now and in the future (Christopher, 1992). Given the growing strategic importance of customer-orientation and of the related issues, one can generally postulate that supply chain networks are strategic networks, i.e. they are comprised of intentionally formed interfirm relationships that are strategically important for the involved firms. Indeed, supply chain networks possess all the important features of strategic networks (Jarillo, 1988) as they involve highly intensive, recurrent and long-term relationships between network members; they are characterised by a pyramidal-hierarchical type of coordination; and they possess a focal firm which coordinates the network.

A focal firm can be defined as the one that possesses prominence and power gained through individual attributes and a central position in the network structure and that uses its prominence and power to perform a leadership role in pulling together the dispersed resources and capabilities of network members (Dhanaraj and Parkhe, 2006: 659).
From the perspective of the focal firm, value must be created in the network, and effective creation of value hinges on deliberate, purposeful coordination efforts (Dhanaraj and Parkhe, 2006; Möller et al., 2005).

The focal firm coordinates the network to fulfill certain tasks (Möller et al., 2005). For example, a task of the focal company is the creation of appropriability regimes that disable 'cheating' within the network and preclude transfer of valuable knowledge to competing networks. Furthermore, given unstable linkages and competitive pressures among network members, another task of the focal firm is to foster network stability. Network stability must be primarily understood as dynamic (not static) stability, which aims for a non-negative growth rate; while allowing for entry and exit of network members. By its strategic choice of partners, a focal firm can significantly change network membership and structure. Through recruitment and brokering activities, the focal firm can control its network position, maintaining its centrality and status (Dhanaraj and Parkhe, 2006).

The above arguments may give an impression that a focal firm is in substantial control of surrounding firms. However, in reality, the focal firm's control over a supply chain network is not exhaustive because the supply chain network involves numerous legally independent organisations. Provided that all network members actively pursue their own self-interests and no member is inert, it is in this context of absence of hierarchical authority that the leadership by the focal firm becomes essential. Thus, although the focal company faces more situations when it is in a more powerful position than other network members, the network management is as much about management of the network as it is about management in the network (Ritter et al., 2004: 177).

The main challenge for the focal actor in managing the supply chain network is adaptation to uncertainty which depends on how the connected relationships are organised (Jap and Ganesan, 2000; Wathne and Heide, 2004). For example, a manufacturer's ability to adapt in a flexible manner to uncertainty in the downstream relationship can be contingent upon its effectiveness in structuring the relationship with its upstream supplier and vice versa. In this regard, Gulati et al. (2005) have posited that adaptation in the procurement relationship involves fulfilment of the coordination and cooperation tasks. The coordination task is the alignment of actions, i.e. enabling a joint action, whereas the cooperation task is the alignment of interests, i.e. motivation of the exchange parties. Furthermore, Hanf and Dautzenberg (2006) have shown that individual and collective interests as well as individual and collective actions are entwined in supply chain networks and, therefore, 
interests and actions must be aligned at the firm, dyadic and network levels simultaneously (Duysters et al., 2004). Both partnering and supply chain management strategies have to be derived from the overall collective strategy (Hanf and Dautzenberg, 2006: 80).

The strategic management literature has mainly addressed collective strategies in the context of their orientation towards reduction of variation in the inter-organisational environment (Bresser and Harl, 1986). However, in the strategic network context, collective strategies aim not only to shape the network processes and relationships but also to achieve certain network goals (Sydow and Windeler, 1998: 268). In a strategic network in which a focal firm is responsible for the correctness of attributes of the final product (Hanf and Dautzenberg, 2006), a collective strategy will usually be goal-oriented. As an example, in 2005 Nestlé formed its milk powder supply chain network in Russia by setting up effective guidelines for managing relationships with suppliers and customers. Following these guidelines, Nestlé enhanced long-term vertical and horizontal cooperation among the network members to address issues related to antibiotics, good dairy farming practices, HACCP, organoleptic quality and taste deviations. As a result, rejected milk powder quantities have decreased from $20 \%$ to $3 \%$ in one year. Nestlé introduced incentives for farmers to produce quality and avoided 6 million euro costs that would have resulted from import substitution. Finally, Nestlé has been successful in selling its confectionery and ice cream products in Russia (Nestlé CT Agriculture, 2006). In this example, the strategies of food safety and chain quality goals, as well as the economic goals of Nestlé and its partners have been achieved. These same themes are considered with respect to the Nestlé network in Alvarez et al. (2010) concerning governance in multi-stakeholder networks in coffee supply and highlight the importance of trust in the development of sustainable relationships.

The notion of goal-orientation by collective strategies can be supported by the findings of organisational studies. For instance, Locke (2004) has shown that the focus on goals generates insight into the design of organisational structures and incentive systems, whereas Ethiraj and Levinthal (2009) have emphasised that goals are necessary to direct and coordinate behaviour. Consequently, we posit that network goals may be used to define what the supply chain network's success is. Beyond that, we suggest that a collective strategy may be perceived as a framework of activities to sustain a network's success because it aims at the achievement of network goals. We further describe the dimensions of network success in detail and develop hypotheses on the interrelatedness of constructs that compose these dimensions.

\section{Framework of supply chain network goals}

Earlier studies on the management of interfirm relationships in networks have explicitly emphasised that the implementation of goals set in networks depends on the extent to which relationships are connected and organised (Anderson et al., 1994; Ritter et al., 2004; Wathne and Heide, 2004). This is especially the case for intentionally developed strategic networks (Möller et al., 2005; Sydow and Windeler, 1998). Intentionality behind strategic networks implies that companies deliberately engage in their design and development to achieve specific goals through these networks. Consequently, there exists an interrelationship between goals and network structure. Goals pursued through a network are assumed to influence the type of member interdependence and the effective 'governance form' (Möller and Svahn, 2003: 205), whereas the relationships among members have to be structured such that the intended goals are achieved (Schreiner et al., 2009). Thus, the collective strategy has to consider both structuring of network relationships (i.e. the alignment of interests and actions) and the achievement of goals of the network.

However, the theorists of collective strategies mainly emphasise orientation towards simultaneous resolution of the cooperation and coordination problems by collaborating partners. At the same time, Möller et al. (2005) emphasise that the goal of the strategic network is one of the core factors that promote understanding of the strategic network management. In strategic networks, collective strategies should aim not only at shaping network processes and relationships per se but also at achieving the specified network outcomes. Therefore, the whole supply chain network has to work as a single entity based on a collective strategy to sustain its advantage over competing supply chain networks. Surprisingly, a systematic literature review reveals that there has been little consideration of collective strategies as a network's plan of actions to achieve certain goals. Also, there has been little research conceptualising the goals of supply chain networks and the role they may play in managing a network.

With respect to the numerous collaborative failures experienced by firms due to goal conflicts (Brinkhoff and Thonemann, 2007; Madhok and Tallman, 1998), it is unlikely that network-level goals are adequately addressed in practice. In general, the lack of understanding of goals pursued through supply chain networks can mislead the supply chain network management in developing and 
implementing collective strategies to achieve goals and, thus, cause failure in sustaining the competitive advantage for the whole supply chain network.

In this context, we present the framework of goal achievement that involves three major components: (1) the achievement of network-level and firm-level goals; (2) the fulfillment of tasks of chain management; and (3) the factors that influence the fulfillment of tasks of chain management (Figure 1). Furthermore, we develop and test empirically ten respective hypotheses.

\section{Goals of network members}

The entwinement of self and collective interests implies that the success of individual network members is critical to the success of the whole network and, conversely, positive outcomes for the whole network contribute to the firm's success. Thus, the success of a supply chain network will involve the achievement of network members' goals which can be addressed in relation to the abovementioned levels of a network. At the firm level, firms are setting their individual goals whereas they are setting the collective goals at the dyadic and network levels. However, our focus on the strategic network as a whole enables us to ignore the dyadic level of analysis. As emphasised by Provan and Kenis (2007: 3), 'interactions related to resource allocation as well as coordination and control of a joint action require that the focus is on the network as a whole'.

Under network-level goals we understand the predefined set of outcomes that are shared by all network members and that can be achieved only if all network members work together. Although such shared goals have rarely been addressed in empirical analyses (Sydow and Windeler, 1998), their achievement can be regarded as the essence of collaboration (Pitsis et al., 2004). Historically, joint development and application of emerging technologies had an impact on network goals; a good example of this is in Sparks and Wagner (2003), who identified information technologies (ECR, CPFR) as the driver of retail exchanges in supply chains. Further examples of network-level goals in the food industry include various aspects of food safety and quality addressing primarily increasing consumer demands and the risk of food scandals, e.g. goals such as total chain quality, end consumer satisfaction, etc. The resolution of such complex, rather non-pecuniary issues involves tight collaboration between all network members (Hingley, 2005). We define network-level goals as the shared outcomes; and in strategic networks they have to be seen as viable and acceptable primarily by the powerful stakeholders (Sydow and Windeler, 1998: 274). As a type of strategic network, a supply chain network (as typified in retailersupplier channels) is most often deliberately established by a powerful chain captain or category manager (Fearne, 1998; O'Keefe and Fearne, 2002), as either distributor- or manufacturer-brand owner, who selects appropriate supply chain partners to develop products under its brand (Belaya and Hanf, 2009; Lindgreen and Hingley, 2003); and where trust in supply chains and networks is paramount. We therefore suggest that the network-level goals are firstly defined by a powerful focal firm. This is reflected in the category management approach concerning the UK grocery retailer Waitrose, described in O'Keefe and Fearne (2002), whereby the retailer engenders category leadership and aligns the supply network to the needs of the consumer.

We do not aim to contest the importance of firm-level goals, i.e. goals which single firms want to achieve for themselves by participating in a network. Instead, we emphasise that goals of the whole supply chain network involve networklevel and firm-level goals.

\section{Goals of cooperation and coordination}

As already mentioned in this paper, one of the objectives of the focal firm is to secure the supply chain network from an unplanned dissolution of relationships. To that end, the network's management should balance the contradictory forces that may work to unsettle the status quo (Das and Teng, 2000: 85). In particular, these contradictory forces are likely to occur in supply chain networks wherein most partners are profit-seeking organisations. As emphasised by Eliashberg and Michie (1984: 75), goals pursued by the parties may be one of the chief determinants of the prevailing level of conflict among those parties. We contend that this statement is also valid to address conflict between the firm and network levels because goals at the firm level and at the network level are set by the different network actors. Although conflict can be a stimulant for some positive outcomes, it is widely argued that organisations perform better when there is more goal consensus than conflict (Provan and Kenis, 2007). According to Doz (1996), consensus among network members largely depends on their perception of compatibility of goals. This perception tends to change over time and generally reflects the extent of interest divergence that arises from persistent organisational and social differences between the network members (Doz et al., 2000; Sarkar et al., 2001). Given this fact, we suggest that the extent to which disagreements among network members affect the achievement of their goals will depend on how successfully the cooperation goal of interest alignment is achieved. 


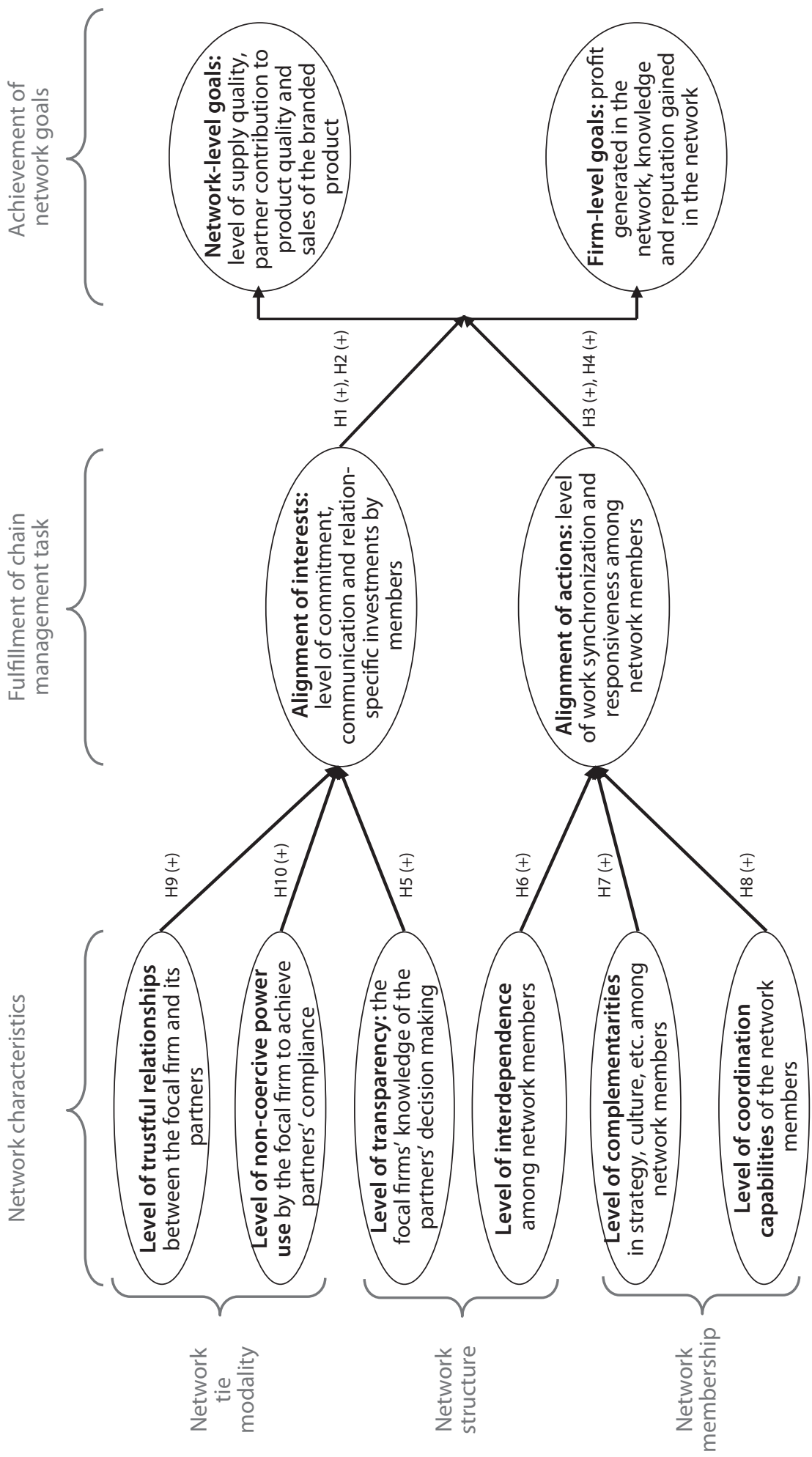

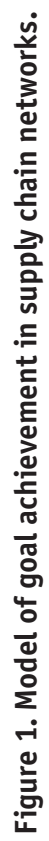


The alignment of interests can be regarded as the establishment of good working relationships among the parties. It addresses factors such as the degree of compatibility of firms' cultures and decision-making styles, a convergence of business views, and other organisational characteristics (Ariño et al., 2001). The alignment of interests of the network members facilitates higher levels of relational capital (i.e. prompts trustful relationships, commitment and low levels of conflict among members) so that confidence in the reliability and integrity of the partners is gained (Kauser and Shaw, 2004). Thus, the alignment of interests largely facilitates the network members' perception of compatibility of network-level goals with firm-level goals. Finally, interest alignment can be defined as the degree to which the members of the organisation, e.g. strategic network, are motivated to behave in line with organisational goals (Gottschalg and Zollo, 2007). We therefore hypothesise that:

\section{H 1: The alignment of interests has a direct positive effect on the achievement of network-level goals}

\section{$H$ 2: The alignment of interests has a direct positive effect on the achievement of firm-level goals}

However, we argue that a supply chain network may fail even if goal conflict is minimised but the network-level and firm-level goals are not achieved due to unsynchronised actions of partners or failure to react in time to each other's requests. Therefore, we suggest that it is also important to achieve the coordination goal of action alignment.

The alignment of actions is necessary to implement concerted, joint actions needed to capitalise on the specialised but interdependent activities of partners (Thompson, 1967). In the context of strategic networks, the firms need to combine and integrate their resources and knowledge across organisational boundaries to create competitive advantage (Gulati et al., 2000). Consequently, there exists high task interdependence between partners that involves managing a complex and overlapping division of labour, linking their specific activities with each other, and making regular mutual adjustments. In such a situation, the greater the joint efforts taken by the partners to manage their activities, and/or the more a partner becomes involved in activities that are traditionally considered the other's responsibility and vice versa, the greater their ability to compete successfully with the marketplace (Schreiner et al., 2009: 1402). Furthermore, the alignment of actions enables organisations to gather high-quality information about the others and creates strong disincentives for opportunistic behaviour (Sarkar et al., 2001). The aligned actions will consequently imply that partners provide timely and reliable responses to each other's work-related needs, being responsive to concerns arising at the firm level of individual partners as well as at the network level. Accordingly, we hypothesise:

\section{H 3: The alignment of actions has a direct positive effect on the achievement of network-level goals}

\section{H 4: The alignment of actions has a direct positive effect on the achievement of firm-level goals}

\section{Determinants of goal achievement}

In order to evaluate strategic networks, Gulati et al. (2000) have proposed considering three types of relational characteristics: network structure, network membership, and tie modality. Network structural characteristics describe the overall pattern of relationships in the network. Network member characteristics include the identities, resources, access, and other features of the network actors. Tie modality is the set of institutionalised rules and norms that govern appropriate behaviour in the network (Gulati et al., 2000: 205). Based on strategic management literature, we draw upon the ideas of Gulati et al. (2000) to analyse respective constructs that reveal how the network structure, network member characteristics, and tie modalities affect the achievement of goals of the network management.

\section{Network structural characteristics}

Supply chain networks consist of a multitude of participating firms. Therefore, the embedded upstream and downstream flows of resources and information have to cross various stages of the chain while the involved firms differ widely in size. As a result, supply chain networks are highly complex systems and they are at high risk of failure (Brito and Roseira, 2005). Hence, reducing complexity is one of the most important tasks. In particular, the supply chain network's management has to consider comprehensively the levels of transparency and interdependence.

Transparency refers to the extent of coverage from upstream industries to downstream industries within the supply chain and how apparent information is to downstream industries (Theuvsen, 2004: 125). Dyer and Singh (1998) have emphasised the role of transparency in transferring knowledge among partners. Because of the complex nature of supply chain networks, their structure is often not made public to all network members, and a feeling of anonymity may arise. This lack of transparency in the network structure increases the probability of free-riding. Transparency is associated with open communication. Therefore, it will be 
primarily conducive to enabling the partners' knowledge of each other's decision-making styles, and certainty each other's intentions. We accordingly hypothesise that:

\section{H 5: Higher levels of transparency have a direct positive effect on the alignment of interests in the whole supply chain network}

Interdependency is acknowledged by firms when they join forces to achieve mutually beneficial outcomes (Mohr and Spekman, 1994). However, beyond the focal firm's set of first-level contacts, there is normally a limited amount of intentionality possible in terms of coordinating the whole network (Gulati et al., 2000). In this context, higher interdependence between the focal firm's partners and their partners makes it possible for the mechanisms employed by the focal firm to coordinate its direct partners to affect the indirect partners too. Thus, a higher level of organisational and task interdependence among network members is necessary to reduce complexity and alleviate uncertainty about the whole network on the part of chain management. Furthermore, higher levels of interdependence among the supply chain network members imply that the network functions as a single entity and is characterised by a joint action to achieve the desired goals. Based on these arguments, we hypothesise:

\section{H 6: Higher levels of interdependence between the focal firm and its direct partners have a direct positive effect on the alignment of actions by the focal firm in the whole supply chain network}

\section{Network membership characteristics}

Research on networks focuses primarily on the interrelationships of firms but single enterprises can be regarded as initial elements of networks because collaborations do not exist without them. Inter-firm collaboration has been widely defined as the means by which firms achieve the ends which would be impossible without working together (Van de Ven, 1976). Each partner in a network dedicates its unique resources and capabilities which, when combined with partners' resources and capabilities, can create inimitable and non-substitutable value (Dyer and Singh, 1998). We therefore express the network membership characteristics by the constructs of firms' complementarities and coordination capabilities.

Network members' complementarities create incentives for firms to collaborate. It is worth noting that collaborations do not inevitably create advantages for the involved firms; instead, especially during their establishment, they absorb resources. Consequently, without the firms' willingness to cooperate, collaboration will not prevail. Thus, firms have to recognise collaboration not as a constraint but as a means to access complementary resources. Furthermore, since supply chain networks are formed to last over a long period, complementarities are essential not only at the beginning of the collaboration but throughout the whole period. Thus, complementarities in culture and strategies (Park and Ungson, 2001) combined with resource complementarities (Dyer and Singh, 1998) will be conducive to action alignment among the network members.

\section{H 7: Higher levels of complementarity among network members have a direct positive effect on the alignment of actions in the whole supply chain network}

Coordination capabilities of firms include the necessary skills and abilities to establish learning routines, build up unique and network-specific knowledge, use modern information technologies, etc. Despite the fact that collaboration is determined by the complementary abilities of the involved firms, only a part of the firm's strategic resources is synergy sensitive (Dyer and Singh, 1998). The need for and the explicit knowledge of firm strategies, culture, and values differ with the firm size, i.e. the network members' understanding of strategic management differs. Additionally, the core competencies and resources of the involved firms often differ, precluding additional rents from collaboration (Dyer and Hatch, 2006). Therefore, coordination capabilities involve the ability to identify and build consensus about task requirements in a given network (Schreiner $e$ t al., 2009). To this effect, higher coordination capabilities of the network members have the potential to enhance their concerted action (Schreiner et al., 2009). As a result, we hypothesise:

\section{H 8: Higher levels of coordination capabilities of the supply chain network's members have a direct positive effect on the alignment of actions in the whole network}

\section{Tie modalities}

The nature of the relationships in a network could be either collaborative or opportunistic, setting the tone for the form of interactions among the actors as either benign or competitive. Whereas we acknowledge that the ultimate tie modalities will be reflected by the extent of interest alignment, it is important to clarify how inherent distinctions among actors are smoothed to preclude the negative consequences of relationships. As is known, in today's procurement relationships, more and more specific investments must be made. Such investments create the chance for the other party to renegotiate the terms of the 
deal (David and Han 2004). To overcome problems of opportunistic behaviour by the network members, some scholars pose that it is feasible to exert power and still have two-way relationships in networks (Cox, 2004; Hingley, 2005; Hingley et al., 2011). The Cox (2004) view for example, is that buyers and suppliers need to understand the power regime that exist between them in supply chain networks because only then can they identify the appropriate way to manage their relationships. Hingley (2005) concurs and proposes that expression of power does not prevent workable network relationships being established and from continuing. Others recommend employing trustbased enforcement mechanisms (Dyer and Singh, 1998). Furthermore, several studies emphasise that the use of non-coercive power (e.g. rewards, recommendations, etc.) has a positive impact on the relationships while the use of coercive power (e.g. punishment, threats, etc.) negatively affects the relationships (Leonidou et al., 2008; Payan and McFarland, 2005). We verify these suggestions by analysing the effects of trustful relationships and non-coercive power on the alignment of interests.

\section{H 9: Higher levels of trustful relationships among the supply chain network's members have a direct positive effect on the alignment of interests in the whole network}

\section{H 10: Higher levels of the use of non-coercive power by the focal firm have a direct positive effect on the alignment of interests in the whole supply chain network}

\section{Methodology}

\section{Survey design}

An in-depth analysis of supply chain networks and problems arising in them might be facilitated by considering the business environments in emerging or transition economies. In those economies, the chain managers still face various infrastructural and financial constraints and, therefore, they may have better possibilities to track the origin of problems arising in interfirm relationships. For example, in the food industry of Central and EastEuropean countries (CEEC), production capacities are often underutilised due to the prevalence of small-scale producers in agricultural production. This category of producers is often unable to meet the quality and quantity requirements of food manufacturers and faces a financial burden for the introduction of logistics management concepts. Additionally, modern IT-infrastructure is seldom used. Such circumstances substantially impede procurement relationships between actors (Gagalyuk and Hanf, 2009).
At the same time, the economic transition in CEEC is characterised by two interrelated processes which are particularly conducive to the development of supply chain networks. These processes are business internationalisation and verticalisation. With regard to business internationalisation, an important remark is that financially strong Western companies have the capability of disrupting the structure of foreign markets and installing their own business ideas in new market environments on a grand scale (Dries and Swinnen, 2004; Dries et al., 2004; Gagalyuk and Hanf, 2009; Swinnen, 2006). It has been observed that the internationalising firms try to arrange a sound supply side for their business abroad. Eventually, these efforts result in verticalisation (Balmann et al., 2006; Boehlje, 1999), i.e. sophistication of the procurement processes and, thus, the use of branding and chain management concepts. As a result, procurement systems evolve where a focal company coordinates the product flows and the information flows by building supply chain networks (Coe and Hess, 2005; KPMG, 2001). In this context, the empirical focus of our study is directed towards Central and Eastern Europe in general and the Ukrainian transitional economy in particular.

To test the model, data was collected from branded food manufacturers in Ukraine. We assume a branded food manufacturer to be a focal company in a network of firms that work together to bring the branded product to the market. The branded food manufacturer is responsible for the attributes of the branded product and is therefore knowledgeable about the network to a large extent. The database of the firms was obtained from a local market research company. In total, 359 firms were included in the database ${ }^{2}$.

A questionnaire was designed based on a review of literature on such variables as strategic partnership and supply chain and strategic alliance performance (see Appendix 1 for the questions and the next section for respective literature sources). Then, the questionnaire was pretested with five food chain specialists. The specialists included buying and quality managers of the international food retailers, a CEO of the international standardisation bodies and a CEO of a non-governmental organisation active in the food business. The respondents were asked to make their comments on the order of questions, wording and format of the questionnaire. Their feedback was used to modify the questionnaire.

\footnotetext{
${ }^{2}$ At time of interviews, there were 627 branded food manufacturing companies in Ukraine.
} 
Telephone interviews were used for data collection. Interviews were conducted in the period from September 1 to November 30, 2009. 101 telephone interviews (with an average duration of 20 minutes) were conducted among 359 branded food manufacturing companies. This resulted in a $28 \%$ response rate. The interviewees were first informed about interviews via e-mail. After receiving their consent, the calls were made at times appointed by the interviewees.

In the process of sampling, we conducted a deliberate (purposeful) selection of the respondents (e.g. Blankertz, 1998; Merkens, 2000; Patton, 1990). Specifically, we employed an expert (concentration) sampling (Fritsch, 2007; Patton, 1990): the persons chosen were in positions with a high level of concentration of appropriate information. More specifically, the interviewees were in the top (i.e. strategic) positions of sales and purchasing departments in their organisations.

\section{Measures}

We turn now to the operationalisation of the variables used in the model. Apart from the literature on performance of supply chains, strategic alliances, strategic partnerships and inter-organisational relationships, we used the results of a pretest in the German specialised fish sector to develop the corresponding measures for the variables included in the model. We further describe these measures with regard to each variable, and Appendix 1 presents the measures in tabular form.

\section{Goals of network members}

These measures assess the degree of goal achievement at the network and firm levels. To develop measures for both network-level and firm-level goals, we first used elaborations of the studies on strategic alliance and supply chain performance and then relied on the pretest ${ }^{3}$. Based on the literature, we obtained the measures of goals which can be regarded as those pursued in supply chain networks. In particular, these were measures such as product quality, overall partner reliability (e.g. quality of supplies by suppliers and quality of services by customers), product traceability (Gellynck et al., 2008), innovations (Möller et al., 2005), profits (Ariño, 2003), common sales (Mohr and Spekman, 1994), knowledge and reputation (Schreiner et al., 2009). Then, the task was to define which of these belongs to network-level goals and which to firm-level goals.

\footnotetext{
${ }^{3}$ Detailed information on the pretest and the study can be provided upon request.
}

As seen, we developed measures based mainly on managerial assessments. Inter-organisational scholars, in particular those involved in the strategic alliance research (e.g. Gulati, 1999; Kale and Singh, 2007), have agreed over time that using managerial assessments to measure inter-organisational performance or alliance success may be one of the most useful ways, regardless of some of the limitations of this approach. The use of this measure has gained acceptance in research, after Geringer and Hebert (1991) demonstrated a positive correlation between alliance performance assessments based on this measure, with assessments based on other objective measures that use accounting or financial data. Furthermore, given the multipurpose nature of inter-organisational relationships, alliances, and networks, Anderson (1990) suggested that instead of using single-item, managerial assessments of performance, success and other constructs, it would be more useful to have a multidimensional scale that included several of these dimensions in it. Accordingly, we use multiple measures for the achievement of network-level goals and firm-level goals as well as for other constructs constituting the model.

The following items were chosen to measure the achievement of 'network-level goals':

- The focal company's satisfaction with the contribution of all suppliers to the quality of the branded product ${ }^{4}$. Over the last decades, it has been recognised that the product quality is no more the responsibility of a single firm; instead, the whole supply chain has to work together to achieve at least a basic level of quality (Hanf and Hanf, 2007; Schiefer, 2007).

- The focal company's satisfaction with the quality of supplies by suppliers. Quality of supplies is a multifaceted aspect that encompasses maintenance of

\footnotetext{
${ }^{4}$ Although several authors point to improvement of the economic efficiency as the main driver of vertical cooperation (Möller and Svahn, 2003; Möller et al., 2005), our measures of network-level goals are primarily associated with quality. The main reason for this was the unwillingness of respondents to speak about issues such as profitability of cooperation, financial status of the partners, etc. We experienced this both in our expert interviews where we interrogated several managers of agri-food companies and in the interviews with the German fish retailers. The respondents mainly referred to commercial confidentiality when we asked them about their profits gained in cooperation with supply chain partners. However, given the increasing requirement for quality by the end consumers, the selected measures can be regarded as appropriate. Furthermore, the economic efficiency can be considered as the driver of cooperation that originates at the firm level. Thus, we have included satisfaction with profits as the measure of a firm-level goal.
} 
necessary product volumes, guaranteeing of preservation and traceability (Schiefer, 2007), etc.

- The focal company's satisfaction with the quality of product-related services by customers. Quality of services by customers involves aspects such as product appearance on the shelf, provision of storage facilities, etc.

- The focal company's satisfaction with the contribution of all customers to sales of the branded product. Sales of the branded product reflect the end consumers' perception of the product quality, line-up and other features.

The measures for the achievement of 'firm-level goals' include the focal company's assessment of:

- Satisfaction among suppliers and buyers with their profits generated within a network (Medlin, 2006).

- Satisfaction among suppliers and buyers with knowledge gained in a network (Schreiner et al., 2009).

- Satisfaction among suppliers and buyers with reputation from cooperation in a network (Schreiner et al., 2009).

\section{Goals of cooperation and coordination}

The tasks of chain management include the cooperation task of the alignment of interests and the coordination task of the alignment of actions. The achievement of 'interest alignment' was operationalised by the following measures:

- The focal company's confidence in reliability of the partners (Schreiner et al., 2009), i.e. certainty that the partners will perform their tasks appropriately over a long term.

- The focal company's assessment of the extent of suppliers' and customers' relation-specific investments that indicates the degree to which suppliers and customers abstain from behaving opportunistically and are committed to and trust in relationships in the network (Dyer and Singh, 1998).

- The focal company's satisfaction with communication within a network. This has been used as a measure of interest alignment because it shows to what extent the network members are open to working together and perceive the working relationships as good (Mohr and Spekman, 1994).

The 'alignment of actions' was measured by:

- The focal company's satisfaction with suppliers' and customers' willingness to perform their operational tasks.

- The focal company's satisfaction with suppliers' and customers' responsiveness (Handfield and Bechtel, 2002) to the requests by the focal company concerning issues such as the timeliness of delivery by suppliers, correctness of merchandising services, timeliness of payments for the supplied products by customers, etc.
Among other things, these items indicate the level of action synchronisation in the network which reflects the extent to which network members are capable of generating rents from the routines developed in the network (Kale et al., 2002). In addition, synchronised actions are important for avoiding coordination costs (Gulati et al., 2005).

\section{Network structural characteristics}

As mentioned in the previous section, the supply chain network's structural characteristics encompass the level of transparency of the network to the focal firm, and the level of interdependence between the focal company and its direct partners as well as between other network members. The 'level of transparency' was measured by:

- The focal company's degree of awareness of the decision rules adopted by its suppliers and customers (Choi and Kim, 2008).

- The focal company's degree of awareness of the decision rules adopted by its suppliers' suppliers and its customers' customers (Choi and Kim, 2008).

The measures of the 'level of interdependence' were drawn from Mohr and Spekman (1994) and Rowley et al. (2000). They included:

- The extent to which the focal firm is able to easily substitute its suppliers and customers (reverse coded).

- The extent to which suppliers and customers are able to substitute the focal firm with another company (reverse coded).

- The extent of dependence between the operational decisions of the focal company's suppliers on the one hand and customers on the other.

\section{Network membership characteristics}

The 'level of complementarities' between network members was measured by:

- The cultural fit between the focal company and its suppliers and customers (Park and Ungson, 2001).

- The strategic fit between the focal company and its suppliers and customers (Park and Ungson, 2001).

The 'level of coordination capabilities' was operationalised by:

- The suppliers' and customers' agreement on task distribution (Schreiner et al., 2009).

- The ability to adopt the focal company's standards (Schreiner et al., 2009). 
Measures of tie modalities

We measured the 'level of trustful relationships' by:

- The focal firm's willingness to always inform its suppliers and customers about future steps in cooperation (Mohr and Spekman, 1994).

- The suppliers' and buyers' perception of favorability of participation in a network (Mohr and Spekman, 1994).

The 'level of use of non-coercive power' was measured by:

- The frequency of awarding bonuses to suppliers and customers by the focal company (Payan and McFarland, 2005).

- The frequency of providing recommendations to suppliers and customers by the focal company (Payan and McFarland, 2005).

\section{Model testing}

To test the model, we used the Partial Least Squares (PLS) technique for Structural Equation Modelling (Wold, 1982) using the SmartPLS software 2.0.1 (Henseler et al., 2009).

Structural Equation Modeling (SEM) techniques such as LISREL and PLS are second generation data analysis techniques (Bagozzi and Fornell, 1982). Overall, SEM techniques test for statistical conclusion validity (Gefen et al., 2000). Contrary to first generation statistical tools such as regression, SEM enables researchers to answer a set of interrelated research questions in single, systematic and comprehensive analysis by modeling the relationships among multiple independent and dependent constructs simultaneously (Gerbing and Anderson, 1988). This capability for simultaneous analysis differs from most first generation regression models such as linear regression, LOGIT, ANOVA, and MANOVA, which can analyse only one layer of linkages between independent and dependent variables at a time (Gefen et al., 2000: 4).

Using first generation regression models two unrelated analyses are required: (1) examining how the items load on the constructs via factor analysis; and then (2) a separate examination of the hypothesised paths, run independently of these factor loadings. SEM permits complicated variable relationships to be expressed through hierarchical or nonhierarchical, recursive or non-recursive structural equations, to present a more complete picture of the entire model (Bullock et al., 1994). The intricate causal networks enabled by SEM characterise real-world processes better than simple correlation-based models. Therefore, SEM is more suited for the mathematical modeling of complex processes to serve both theory and practice (Gefen $e$ t al., 2000).
Unlike first generation regression tools, SEM not only assesses the structural (inner) model - the assumed causation among a set of dependent and independent constructs - but, in the same analysis, also evaluates the measurement (outer) model - loadings of observed items (measurements) on their expected latent variables (constructs). As can be seen in Figure 1, the model involves 10 latent variables (constructs), which are operationalised by respective items (manifest variables) as described in Section 5 of this paper and systemised in Appendix 1. Manifest variables that make no significant contributions to the respective latent variables are progressively removed and the analysis is repeated until all the manifest variables are significant (Gyau and Spiller, 2009).

The combined analysis of the measurement and the structural model enables measurement errors of the observed variables to be analysed as an integral part of the model, and factor analysis to be combined with the hypotheses testing. The result is a more rigorous analysis of the proposed research model and, very often, a better methodological assessment tool. Thus, in SEM, factor analysis and hypotheses are tested in the same analysis. SEM techniques also provide fuller information about the extent to which the research model is supported by the data than in regression techniques (Gefen et al., 2000: 5).

Our decision to use the PLS technique was based on the fact that, in contrast to such covariance-based approaches as LISREL, the variance-based PLS approach is adequate for causal modeling applications whose purpose is prediction and/or theory building. Given that the achievement of network-level goals is a new construct included in analysis and the effects of the alignment of interests and alignment of actions on this construct have not been tested up to now, PLS seems to be a suitable approach. Additionally, the simultaneous effects of the alignment of interests and alignment of actions on both network-level and firmlevel goals have not been analysed before. Furthermore, scholars have rarely addressed the conditions under which interest alignment can generate competitive advantage (Gottschalg and Zollo, 2007). Thus, by modeling the effects of the specific network conditions, i.e. network structural characteristics, network member characteristics and tie modality on the constructs of the alignment of interests and the alignment of actions, we also contribute to theory building. Also, our decision to use PLS was based on its advantages compared to other techniques, i.e. the possibility to analyse small size samples in the absence of distribution assumptions. 


\section{Results}

\section{Testing the measurement model}

As mentioned above, the fit of the model in PLS is evaluated with regard to the structural (inner) and the measurement (outer) models. Individual item reliabilities and convergent validity of the model provide information about the fit of the measurement (outer) model. The individual item reliabilities are evaluated via the factor loadings of the items on their constructs. According to Hair et al. (1998), an item is considered insignificant and removed from the model if its factor loading is less than 0.4. Based on this criterion, the measurement model generally demonstrates a good fit; in particular the construct of network-level goals demonstrates high reliability and validity of the items. Of the 48 items used to operationalise the latent variables in the model, seven were removed. Table 1 demonstrates the removed items as well as their respective latent constructs.
We also calculated the Cronbach's $\alpha$ and composite reliability criteria to evaluate internal consistency of the measurements. The Cronbach's $\alpha$ measures exceed the recommended criterion of 0.7 for all constructs except for the constructs of alignment of interests, alignment of actions, level of coordination capabilities, and level of transparency (Table 2).

However, the composite reliability index is more reliable in assessing convergent validity because it takes into account the relative weights of the various indicators in a latent construct while Cronbach's $\alpha$ assumes equal weights (Gyau and Spiller, 2009). Thus, because all the composite reliability indices are above 0.7 (Table 2), we made a decision based on the composite reliability indices and retained the constructs of alignment of interests, alignment of actions, level of coordination capabilities and level of transparency in the analysis.

Table 1. The items removed from the model as insignificant.

Item

Respective construct

To what extent do you think your current customers are satisfied with knowledge received Achievement of firm-level goals from your company?

To what extent do you think your current customers are satisfied with the reputation of Achievement of firm-level goals working together with your company?

How satisfied are you with the mutual information exchange with your current customers? Alignment of interests

Most of our suppliers know what they have to do to meet our standards

Level of coordination capabilities

How often do you provide your customers with specific recommendations that help them Level of use of non-coercive power

meet your requirements?

We are knowledgeable enough about the decision-making styles of our customers Level of transparency

If necessary, we could substitute our customers quite easily

Level of interdependence

Table 2. Results of the assessment of the measurement model: Cronbach's $\alpha$, Composite Reliability, and AVE.

\begin{tabular}{|c|c|c|c|}
\hline Latent variables & Cronbach's $\alpha$ & Composite reliability & AVE \\
\hline Achievement of network-level goals & 0.796 & 0.760 & 0.643 \\
\hline Achievement of firm-level goals & 0.749 & 0.745 & 0.563 \\
\hline Alignment of interests & 0.645 & 0.755 & 0.593 \\
\hline Alignment of actions & 0.640 & 0.770 & 0.561 \\
\hline Level of complementarities & 0.835 & 0.782 & 0.504 \\
\hline Level of coordination capabilities & 0.574 & 0.746 & 0.564 \\
\hline Level of use of non-coercive power & 0.770 & 0.807 & 0.559 \\
\hline Level of trustful relationships & 0.796 & 0.856 & 0.603 \\
\hline Level of transparency & 0.641 & 0.731 & 0.532 \\
\hline Level of interdependence & 0.717 & 0.738 & 0.532 \\
\hline
\end{tabular}


The convergent validity was estimated by calculating the average variance extracted (AVE) scores. The recommended threshold of 0.5 (Bagozzi and Yi, 1988) was exceeded for all the constructs indicating that the chosen indicators are explained by their respective constructs (Table 2).

\section{Testing the structural model}

The fit of the structural (inner) model was evaluated by the discriminant validity criterion which means that every construct is significantly different from the others. The first way to analyse discriminant validity is a comparison of item loadings and cross loadings. If all loadings are higher than cross loadings, then the construct significantly differs from the others. The results of the comparison of loadings of the remaining items with the cross loadings indicate a good fit of the structural model.

The second way to assess discriminant validity is to compare the square root of the AVE with the correlation between the construct and the other constructs. The square root of the AVE should be higher than the correlation between the constructs (Gyau and Spiller, 2009). The results of this comparison also support the fit of the inner model (Table 3).

The structural model was evaluated based on the $\mathrm{R}^{2}$ and the significance of the path coefficients. The variances explained $\left(R^{2}\right)$ for each of the endogenous variables were as follows: achievement of network-level goals 0.542 , achievement of firm-level goals 0.199, alignment of interests 0.305, and alignment of actions 0.237 (see numbers within the ellipses of respective constructs in Figure 1). Considering the complexity of the research model, the results indicate a good fit. Rather low $\mathrm{R}^{2}$ values for the achievement of firmlevel goals and the alignment of actions can be caused not only by the complex nature or manifold determinants of these constructs but also by some inconsistency in the operationalisation of these constructs. As demonstrated by the results in Table 1, this might particularly concern the construct of the achievement of firm-level goals.

To determine the significance of the path coefficients, Falk and Miller (1992) have recommended multiplying the standardised path coefficients by the correlation coefficient between the latent variables as an approximate measure of the variance of the construct explained by the latent predictive variable. Using this approach, one might consider values of less than $1.5 \%$ as not making a significant contribution to their respective latent variables (Gyau and Spiller, 2009: 30). Thus, we accepted eight out of the ten hypotheses that were formulated. Hypothesis $\mathrm{H} 7$ could not be accepted based on this criterion, and Hypothesis H6 was rejected because of an unexpected sign obtained. The results are shown in Table 4.

We have used bootstrap method with 200 re-sampling to define the significance of the path coefficients. The path coefficients and their significance based on t-values at the $P<0.05$ level are also shown in Table 4. Based on this criterion, we accepted seven out of the ten hypotheses that were formulated. Specifically, Hypotheses $\mathrm{H} 2$ and $\mathrm{H} 7$ could not be accepted because the contribution of the constructs of alignment of interests and level of complementarities was

Table 3. Results of the assessment of the structural model: correlations of the latent variables and the AVE square roots.

\begin{tabular}{lrrrrrrrrrr}
\hline & \multicolumn{1}{l}{ AA ${ }^{1}$} & \multicolumn{1}{l}{ AI } & \multicolumn{1}{l}{ C } & CC & \multicolumn{1}{l}{ FL } & I & NL & P & TR & T \\
AA & 0.749 & & & & & & & & & \\
AI & 0.033 & 0.770 & & & & & & & & \\
C & 0.176 & 0.205 & 0.710 & & & & & & & \\
CC & 0.408 & 0.167 & 0.351 & 0.751 & & & & & & \\
FL & 0.407 & 0.195 & 0.045 & 0.181 & 0.750 & & & & & \\
I & -0.405 & -0.177 & -0.065 & -0.413 & -0.292 & 0.729 & & & & \\
NL & 0.678 & 0.308 & -0.027 & 0.194 & 0.526 & -0.238 & 0.802 & & & \\
P & 0.137 & 0.301 & 0.083 & 0.052 & -0.021 & 0.078 & 0.142 & 0.748 & & \\
TR & 0.147 & 0.275 & -0.040 & 0.112 & 0.089 & 0.012 & 0.305 & 0.206 & 0.729 & \\
T & -0.191 & 0.384 & -0.092 & -0.174 & 0.163 & 0.018 & 0.030 & -0.114 & 0.034 & 0.777 \\
\hline
\end{tabular}

\footnotetext{
${ }^{1} \mathrm{AA}$ : alignment of actions; AI: alignment of interests; C: level of complementarities; CC: level of coordination capabilities; FL: achievement of firm-level goals; I: level of interdependence; NL: achievement of network-level goals; P: level of non-coercive power use; TR: level of transparency; T: level of trustful relationships.
} 
Table 4. Results of the assessment of the structural model.

\begin{tabular}{|c|c|c|c|c|c|}
\hline Hypotheses & Constructs & $\begin{array}{l}\text { Expected } \\
\text { sign }\end{array}$ & $\begin{array}{l}\text { Beta (path) } \\
\text { coefficients } \\
\text { (b) }\end{array}$ & $\begin{array}{l}\text { Correlation } \\
\text { coefficient } \\
\text { (r) }\end{array}$ & $b \times r$ \\
\hline $\mathrm{H} 1$ & Alignment of interests $\rightarrow$ Network-level goals & + & $0.286^{* * *}$ & 0.308 & 0.088 \\
\hline $\mathrm{H} 2$ & Alignment of interests $\rightarrow$ Firm-level goals & + & 0.182 & 0.195 & 0.035 \\
\hline H3 & Alignment of actions $\rightarrow$ Network-level goals & + & $0.669^{* * *}$ & 0.678 & 0.454 \\
\hline $\mathrm{H} 4$ & Alignment of actions $\rightarrow$ Firm-level goals & + & $0.401^{* * *}$ & 0.407 & 0.163 \\
\hline H5 & Level of transparency $\rightarrow$ Alignment of interests & + & $0.198^{* *}$ & 0.275 & 0.054 \\
\hline H6 & Level of interdependence $\rightarrow$ Alignment of actions & + & $-0.291^{* * *}$ & -0.405 & 0.118 \\
\hline H7 & Level of complementarities $\rightarrow$ Alignment of actions & + & 0.064 & 0.176 & 0.011 \\
\hline $\mathrm{H} 8$ & Level of coordination capabilities $\rightarrow$ Alignment of actions & + & $0.265^{* * *}$ & 0.408 & 0.108 \\
\hline H9 & Level of trustful relationships $\rightarrow$ Alignment of interests & + & $0.412^{* * *}$ & 0.384 & 0.158 \\
\hline $\mathrm{H} 10$ & Level of use of non-coercive power $\rightarrow$ Alignment of interests & + & $0.306^{* * *}$ & 0.301 & 0.092 \\
\hline
\end{tabular}

insignificant. Additionally, Hypothesis $\mathrm{H} 6$ was rejected due to the unexpected sign. Overall, by comparing the results obtained through the Falk and Miller's (1992) method with those by the bootstrap method, one can postulate that the findings with respect to Hypothesis $\mathrm{H} 2$ have to be interpreted with some caution as they are controversial. We discuss the results in the next section.

\section{Discussion, conclusions and research implications}

The results support the vast majority of our theoretical suppositions and, most importantly, reveal that the achievement of network-level goals is to a large extent explained by how well both cooperation and coordination problems are solved (Hypotheses $\mathrm{H} 1$ and $\mathrm{H} 3$ supported). This finding underscores the strategic value of achieving network-level goals for the success of a whole supply chain network and extends the existing frameworks of chain management by calling for more attention to network-level goals.

There are a few major points to be mentioned in this regard. First, network-level goals may play an important role in creating long-term collaborative advantage because, as collective goals, they serve as an integrating mechanism that creates initial conditions for collaboration and stabilises the relationships if there is agreement on them. They are the glue that holds all the network members together.

Second, in strategic networks in general and in supply chain networks in particular, network-level goals do not represent just abstract views that are introduced by the focal firm and have to be shared by other network members, for the sake of integration. They are concrete goals to be achieved through collaboration of all the network members and, if not achieved, may be a cause of network dissolution or relationship break-off. In a strategic network, network-level goals are an inherent characteristic. They can be regarded as one of the departing points or even the main departing point for the development and implementation of the whole network's collective strategy. Prior to entering a supply chain network, potential members have to understand that the network is not just a lever for them to achieve their individual goals but it aims also to achieve certain goals by itself.

In essence, this premise provides an opportunity to adopt a somewhat different perspective of collective strategies. The prevailing idea has been that the collective strategy represents a collaboratively developed plan of actions aimed at reducing variation in the interorganisational environment, i.e. dealing with uncertainty that arises from the behaviour of interdependent organisations caused by their endeavours to achieve firm-level goals. However, as our results demonstrate, members of supply chain networks also pursue certain goals at the network level. In this context, we extend the existing idea of collective strategies along two lines. First, a collective strategy should address not only the relationships between firm-level goals of network members but also the relationships between network-level and firmlevel goals. Second, a collective strategy has to be seen as a plan of actions to achieve network-level and firm-level goals simultaneously. 
With regard to goal alignment, we think that an important task of the focal company is to address the relationships that can occur between network-level and firm-level goals - the issue that has been under-researched in strategic networks due to scant attention paid to network-level goals. However, it seems that, like the relationships between individual goals of network members, the relationships between networklevel and firm-level goals tend to be either complementary or conflicting. In this regard, the focal company has to deal primarily with conflicting relationships as they lead to problems for the whole network. For example, a networklevel goal such as product quality may not be the focus of all firms that participate in the network. Moreover, it can be rather difficult to make all network members aware of network-level goals, in that they are collective by the directionality of effort of all; but they are most often set by the focal firm. In order to reduce such risks, focal companies have to formulate network-level goals clearly and address them explicitly.

Furthermore, even if the awareness of network-level goals is gained, they may be a source of conflict and interfirm rivalry. Brinkhoff and Thonemann (2007) have found that unclear definition of collective goals and lack of agreement on them are the main reasons why $50 \%$ of interorganisational projects in supply chains fail. Because conflict resolution and goal consensus are the tasks of alignment of interests, focal companies have to deal with this extended conflict dimension, i.e. conflict between network-level and firm-level goals, through adoption of appropriate partnering strategies.

We suggest that the extended focus on the goals of a supply chain network which includes network-level goals alongside firm-level goals enables a vision of where the network itself aims to be and how effective it is. Especially, if one takes notice of a focal firm which is responsible for the correctness of attributes of the final product in a supply chain network, 'the network-visioning capability' (Möller et al., 2005: 1279) is important. From the strategic management standpoint, the focal firm can gain strategic advantage if network-level goals are achieved but it can sustain this advantage only if firm-level goals of the network members are achieved. In turn, the other network members can gain strategic advantage if they achieve their individual goals and they can sustain this advantage if they achieve network-level goals.

A contribution of our study is to show that the simultaneous achievement of network-level and firm-level goals requires strong coordination capabilities of network members. The results of our model testing indicate that the abilities of the network members to make effective decisions on how the network should function make a significant contribution to the alignment of actions (Hypothesis H8 supported). In turn, the alignment of actions has a significant positive effect on the achievement of both network-level and firm-level goals (Hypothesis $\mathrm{H} 4$ supported), indicating that the joint

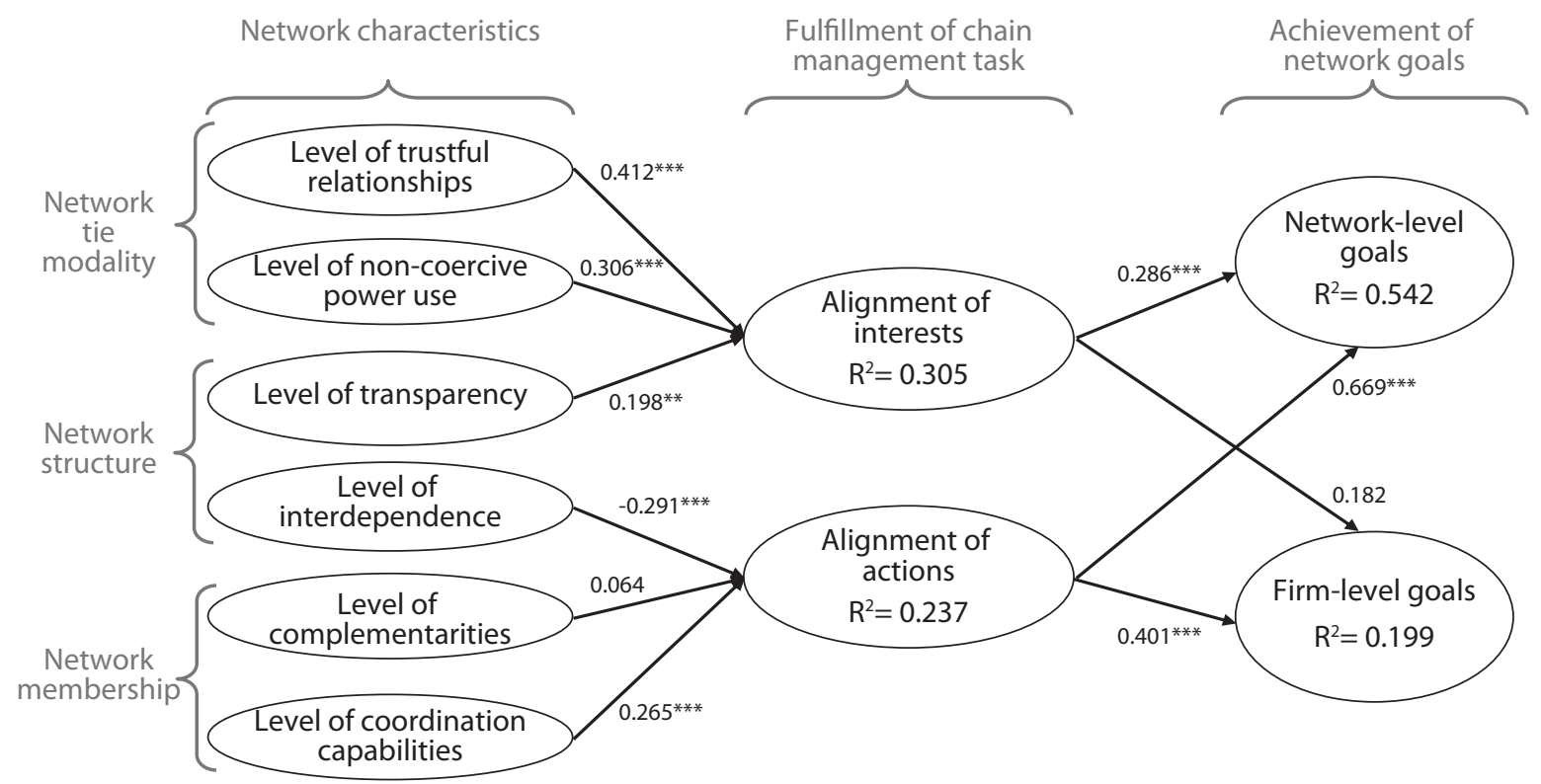

Figure 2. Results of the model testing. 
action as a collective construct is closely linked to individual constructs in business relationships (Medlin, 2006). This implies that successful chain management has beneficial outcomes also at the firm level of suppliers and customers, although the respective effect (see path coefficients in Table 4 and Figure 2) is weaker at the firm level than at the network level ${ }^{5}$.

The results also show some unexpected findings enabled by the PLS property to analyse all the relationships in the model simultaneously. Calculations with regard to the Hypothesis $\mathrm{H} 2$ produce controversial results but the tendency is that the alignment of interests has a small positive effect on the achievement of firm-level goals of the network members ${ }^{6}$. Importantly, this result contradicts the findings of the strategic management scholars, e.g. Mentzer et al. (2000), Gulati et al. (2005), Gottschalg and Zollo (2007) and others who have observed large positive effects of interest alignment on the achievement of individual firm's goals. We explain this contradiction by the expanded theoretical focus from the dyadic level to the network level, i.e. by the presence of network-level goals in the model. In the dyadic context, it is difficult to recognise the other connected relationships of the same network and, thus, to make complete conclusions about how the relationships should be organised. On account of this, our results show that the focal firm's efforts to align the interests in both downstream and upstream relationships have little effect on the achievement of the individual firm-level goals of buyers and suppliers.

In some cases, focal firms can use this condition to align the interests of their upstream and downstream partners such

\footnotetext{
${ }^{5}$ The results, however, must be accepted with some caution as we surveyed only focal firms. For example, the focal firm's suppliers or buyers could have expressed different opinions about satisfaction with achievement of their firm-level goals (Emiliani, 2003; Kim et al., 1999). This limitation is caused by the strategic network approach we followed in the study by assuming that the focal firm is concerned with the management of the network and is, therefore, knowledgeable about goals pursued through the network.

${ }^{6}$ Cohen (1988) proposes evaluating the criterion of effect size for each effect in the path model. The effect size $f^{2}$ is calculated as the increase in $R^{2}$ relative to the proportion of variance of the endogenous latent variable that remains unexplained: $f^{2}=$ $\left(R_{\text {included }}^{2}-R_{\text {excluded }}^{2}\right) /\left(1-R_{\text {included }}^{2}\right)$. Values of $0.02,0.15$, and 0.35 signify small, medium, and large effects, respectively. To be able to better explain the effect of the alignment of interests on the achievement of firm-level goals, we have calculated its size: $f^{2}=(0.542-0.479) /(1-0.542)=0.14$. The value of $f^{2}=0.14$ indicates a small effect.
}

that the achievement of individual goals of the partners is complicated. For example, they can require relationshipspecific investments for the establishment of a sufficient infrastructure that makes it problematic for the partners to obtain profits from the relationships in the short run.

Another result can also be regarded as unexpected. The alignment of actions is negatively affected by higher levels of interdependence and, thus, Hypothesis H6 is rejected. Although interdependence is usually addressed as an enabler of collaboration (Doz et al., 2000; Schreiner et al., 2009), it is evident that the focal companies consider higher dependence on the supply chain partners unfavorable and try to have enough opportunities to substitute their partners.

In this context, one has to take the specifics of the research setting into account. The result of Hypothesis $\mathrm{H} 6$ indicates that the issue of supplier and customer compliance is still severe in the Ukrainian agri-food business. Despite the wide scope of vertical coordination practices and the growing use of chain management concepts, the business environment in Ukraine is highly volatile with persisting infrastructural problems. This precludes interlocking of the actions of network members needed to capitalise on the specialised but interdependent activities. At the same time, the situation can be quite different in stable business environments where companies are not afraid of engaging in supportive action, establishing necessary routines, and making mutual adjustments to the distribution of tasks.

We therefore postulate that supply chain networks in the Ukrainian agri-food business require modification of the 'imported' chain management concepts. Agri-food chains in Ukraine exhibit frequent contract breaches in order to satisfy short-term pecuniary interests. This leads to supply disruptions and induces costs for the parties. Not least of all, such difficulties arise due to an unfavourable institutional environment: property rights are weakly protected, contract enforcement is poor, etc. In this case, the motivational problem can be solved by using self-enforcement agreements that involve reputational elements. The results of our model testing indicate that gaining a reputation from the cooperation by suppliers is one of the firm-level goals. Symptomatically for CEEC, collaboration with some suppliers can be established based on suppliers' reputation quests. Consider a strong reputation effect of a well-known multinational brand on small local suppliers. Furthermore, being involved in a collaboration with big brand-owners is recognised as an advantage because small suppliers believe they minimise their income risk by working together with financially strong companies. Furthermore, the negative effect of interdependence on the alignment of actions can 
be caused by the fact that our manifest variables reflect interdependencies in the whole supply chain network. Accordingly, higher dependence of the focal company on the relationship with a supplier implies higher contingency upon volatilities in a supplier's relationships with its suppliers. Consequently, action alignment appears to be complicated. This conclusion is tribute to a growing interest in the structural embeddedness issues on the part of supply chain management scholars (Choi and Kim, 2008). They emphasise that the buying companies should go beyond evaluating and managing suppliers as if the suppliers existed in isolation; instead they also have to consider the suppliers' suppliers. Here, the issue of chain transparency gains in importance and our results support this notion because higher levels of transparency have a significant positive effect on the alignment of interests. Although the surveyed focal firms belong to the different sectors which, accordingly, exhibit (and often require) ${ }^{7}$ different levels of chain transparency, the issue of transparency in the supply chain network has to be addressed at the strategic management level; regardless of the sector in which a firm operates. The reason is that transparency among partners enables transfer of valuable knowledge and precludes free-riding (Dyer and Singh, 1998).

In addition, interest alignment is subject to significant positive effects by higher levels of trustful relationships and non-coercive power as proposed by Hypotheses $\mathrm{H} 9$ and $\mathrm{H} 10$, respectively. These results are consistent with the findings of earlier research if considered both separately and simultaneously. For example, Handfield and Bechtel (2002) have shown that trustful relationships have a significant effect on partner responsiveness, whereas Leonidou et al. (2008) have found that the exercise of non-coercive power is negatively related to conflict in interfirm working relationships. Additionally, Hasanagas (2004) has illustrated

\footnotetext{
${ }^{7}$ Deimel et al. (2008) have compared transparency of the dairy and pork supply chains in Germany. They have found that the transparency profiles of the dairy and pork chains are quite different and that transparency is somewhat higher in the dairy chain than in the pork business. Compared to pork production, transparency in the dairy chain was positively influenced by a lower number of transaction partners and a tendency toward a longer-term governance structure in transactions due to more specific investments. Furthermore, the explicitness and clearness of information exchanged and the levels of trust and commitment were higher in the dairy sector. On the other hand, the pork chain has revealed advantages over the dairy chain due to higher satisfaction with supply chain partners' performance, a more balanced distribution of power between the partners, and a lower frequency of transactions.
}

that the stronger inter-firm trust is, the more effective noncoercive power mechanisms become to achieve compliance of the partner.

The remaining Hypothesis (H7) proposed that network members' complementarities have a direct positive effect on coordination. However, the effect was insignificant. The reason may be the fact that supply chain networks represent well-defined value systems (Möller et al., 2005) where firms from different stages of the supply chain possess complementary resources and perform complementary tasks. The strategic complementarity (Dyer and Singh, 1998: 668) between network members is thus predefined, implying that the existing complementarities are wellknown to members and can have only a minor effect on the alignment of actions.

However, once a focal firm has partners with the requisite complementary strategic resources, a challenge is to develop organisational complementarity (Dyer and Singh, 1998: 668) - the organisational mechanisms necessary to enable the alignment of actions. In a case where the need for the development of organisational complementarity arises, one of the main factors the focal firm has to consider is the partners' coordination capabilities (Kale et al., 2002). The result with regard to Hypothesis H8 supports this proposition, indicating that the suppliers' and customers' ability to work according to standards and to identify and build a consensus around task requirements contributes to the successful resolution of coordination problems and the establishment of a joint action. This result coincides with the findings of Schreiner et al. (2009) who have confirmed the positive link between alliance management capability and joint action.

Two general conclusions can be made based on the results of empirical analysis. First, network-level goals must be considered alongside firm-level goals in supply chain networks. Network-level goals are subject to major effects on the part of chain management and have to be of particular interest for focal firms that are responsible for the development and implementation of collective strategies.

Second, we postulate that supply chain networks in the Ukrainian agri-food business require modification of the 'imported' chain management concepts. Although PLS does not allow for conclusions about the whole population, representativeness of the sample is not of major importance if the task is to examine the hypothesised relationships (Berekoven et al., 1999; Diekmann, 1999). The analysis of the hypothesised relationships in our model reveals that the investigated supply chain networks (the active sample 
of 101 respondents of 627 branded food manufacturers in Ukraine in total) are characterised by a negative effect of higher interdependence among members on the alignment of their actions. This finding can be explained by high volatility of the business environment and infrastructural problems (Gagalyuk and Hanf, 2009). Additionally, there might be a lack of capabilities by focal firms with regard to capturing the whole supply chain network in order to address the existing interdependencies as the issue of the network level of analysis which reflects the complexity of the network structure. However, the model could and should be applied in the context of other countries (and networks of supply chains between countries, as is more typical in globalised markets). We would like to see a repetition of the model in food networks of other, and more developed and mature food markets and its application to other (non-food) contexts. This could be most effectively and comparatively applied in countries in a similar position of development and those in the process of incorporating 'Western' management, network and organisational concepts (such as the BRIC: Brazil, Russia, India, China countries). These too express the volatility and idiosyncrasies of growing nations. There are some illustrations of the challenges of this kind of network development in food and retailing in such contexts. Viera et al. (2009), for example, investigate the Brazilian grocery supply network concerning collaborative activity. Other non-food sectors that may benefit from such a network perspective could include the clothing industry, which alongside food and grocery is a frequently cited area.

\section{References}

Alvarez, G., C. Pilbeam and R. Wilding, 2010. Nespresso AAA sustainable quality program: an investigation into the governance dynamics in a multi-stakeholder supply chain network. Supply Chain Management, 3(4): 214-231.

Anderson, E., 1990. Two firms, one frontier: on assessing joint venture performance. Sloan Management Review, 31(2): 19-30.

Anderson, J.C., H. Håkansson and J. Johanson, 1994. Dyadic business relationships within a business network context. Journal of Marketing, 58(4): 1-15.

Ariño, A., 2003. Measures of strategic alliance performance: an analysis of construct validity. Journal of International Business Studies, 34(1): 66-79.

Ariño, A., J. de la Torre and P.S. Ring, 2001. Relational quality: managing trust in corporate alliances. California Management Review, 44(1): 109-131.

Bagozzi, R. and Y. Yi, 1988. On the evaluation of structural equation models. Journal of the Academy of Marketing Science, 13(3): 989-1006.
Bagozzi, R.P. and C. Fornell, 1982. Theoretical concepts, measurement, and meaning. In: Fornell, C. (ed.) A second generation of multivariate analysis (vol. 2). Praeger, Santa Barbara, CA, USA, pp. 5-23.

Balmann A., K. Dautzenberg, K. Happe and K. Kellermann, 2006. On the dynamics of structural change in agriculture - internal frictions, policy threats and vertical integration. Outlook on Agriculture, 35: 115-121.

Belaya, V. and J. H. Hanf, 2009. The two sides of power in businessto-business relationships: implications for supply chain management. Marketing Review, 9(4): 361-381.

Berekoven, L., W. Eckert and P. Ellenrieder, 1999. Marktforschung: Methodische Grundlagen und praktische Anwendung (8. Auflage), Gabler, Wiesbaden, Germany.

Blankertz, L., 1998. The value and practicality of deliberate sampling for heterogeneity: a critical multiplist perspective. American Journal of Evaluation, 19(3): 307-324.

Boehlje, M., 1999. Structural changes in the agricultural industries: How do we measure, analyze and understand them? American Journal of Agricultural Economics, 81(5): 1028-1041.

Bresser, R.K.F. and J.E. Harl, 1986. Collective strategy: vice or virtue? Academy of Management Review, 11: 408-427.

Brinkhoff, A. and U.W. Thonemann, 2007. Perfekte Projekte in der Lieferkette. Harvard Business Manager, 7: 6-9.

Brito, C. and C. Roseira, 2005. A model for understanding supply chain networks. Journal on Chain and Network Science, 5(2): 55-63.

Bullock, H.E., L.L. Harlow and S.A. Mulaik, 1994. Causation issues in structural equation modeling research. Structured Equation Modeling, 1(3): 253-267.

Choi, T.Y. and Y. Kim, 2008. Structural embeddedness and supplier management: a network perspective. Journal of Supply Chain Management, 44(4): 5-13.

Christopher, M.G., 1992. Logistics and supply chain management, Pitman, London, UK.

Coe, N.M. and K. Hess, 2005. The internationalization of retailing: implications for supply network restructuring in East Asia and Eastern Europe. Journal of Economic Geography, 5: 449-473.

Cox, A., 2004. The art of the possible: Relationship management in power regimes and supply chains. Supply Chain Management, $9(5): 346-356$.

Das, T.K. and B-S. Teng, 2000. Instabilities of strategic alliances: an internal tensions perspective. Organization Science, 11(1): 77-101.

David, R.J. and S-K. Han, 2004. A systematic assessment of empirical support for transaction cost economics. Strategic Management Journal, 25(1): 39-58.

Deimel, M., M. Frentrup and L. Theuvson, 2008. Transparency in food supply chains: empirical results from German pig and dairy production. Journal on Chain and Network Science, 8: 21-32.

Dhanaraj, C. and A. Parkhe, 2006. Orchestrating innovation networks. Academy of Management Review, 31(3): 659-669. 
Diekmann, A., 1999. Empirische Sozialforschung, Rowohlt Taschenbuch Verlag, Reinbeck bei Hamburg, Germany.

Doz, Y.L., 1996. The evolution of cooperation in strategic alliances: initial conditions or learning processes? Strategic Management Journal, 17: 55-83.

Doz, Y.L., P.M. Olk and P. S. Ring, 2000. Formation processes of R\&D consortia: which path to take? Where does it lead? Strategic Management Journal, 21(3): 239-266.

Dries, L. and J. Swinnen, 2004. Foreign direct investment, vertical integration and local suppliers: evidence from the Polish dairy sector. World Development, 32(9): 1525-1544.

Dries, L., T. Reardon and J. Swinnen, 2004. The rapid rise of supermarkets in Central and Eastern Europe: implications for the agrifood and rural development. Development Policy Review, 22(5): 525-556.

Duysters, G., K.H. Heimeriks and J.A. Jurriens, 2004. An integrated perspective on alliance management. Journal on Chain and Network Science, 4(2): 83-94.

Dyer J.H. and N.W. Hatch, 2006. Relation-specific capabilities and barriers to knowledge transfers: creating advantages through network relationships. Strategic Management Journal, 27(8): 701-719.

Dyer, J.H. and H. Singh, 1998. The relational view: cooperative strategy and sources of interorganizational competitive advantage. Academy of Management Review, 23(4): 660-679.

Eliashberg, J. and D.A. Michie, 1984. Multiple business goals sets as determinants of marketing channel conflict: an empirical study. Journal of Marketing Research, 21(1): 75-88.

Emiliani, M.L., 2003. The inevitability of conflict between buyers and sellers. Supply Chain Management, 8(2): 107-115.

Ethiraj, S.K. and D. Levinthal, 2009. Hoping for A to Z while rewarding only A: complex organizations and multiple goals. Organization Science, 20(1): 4-21.

Falk, R.F. and N.B. Miller, 1992. A primer for soft modelling. The University of Akron, Akron, OH, USA.

Fearne, A., 1998. The evolution of partnerships in the meat supply chain: Insights from the British beef industry. Supply Chain Management, 3(4): 214-231.

Ford, I.D., 1990. Understanding business markets: interactions, relationships and networks. Academic Press, San Diego, CA, USA.

Fritsch, N., 2007. Erfolgsfaktoren im Stiftungsmanagement. Erfolgsfaktorenforschung im Nonprofit-Sektor. Gabler, Wiesbaden, Germany.

Gagalyuk, T. and J.H. Hanf, 2009. Impact of retail internationalization on agribusiness: the case of Ukraine. Journal of East-West Business, 15(2): 96-118.

Gefen, D., D.W. Straub and M.-C. Boudreau, 2000. Structural equation modelling and regression: guidelines for research practice. Communications of the Association for Information Systems, 4(7): 1-78.
Gellynck, X., A. Molnár and L. Aramyan, 2008. Supply chain performance measurement: the case of the traditional food sector in the EU. Journal on Chain and Network Science, 8(1): 47-58.

Gerbing, D.W. and J.C. Anderson, 1988. An updated paradigm for scale development incorporating unidimensionality and its assessment. Journal of Marketing Research, 25(2): 186-192.

Geringer, M. and L. Hebert, 1991. Measuring performance of international joint ventures. Journal of International Business Studies, 22(2): 249-263.

Gottschalg, O. and M. Zollo, 2007. Interest alignment and competitive advantage. Academy of Management Review, 32(2): 418-433.

Gulati, R., 1999. Network location and learning: the influence of network resources and firm capabilities on alliance formation. Strategic Management Journal, 20(5): 397-420.

Gulati, R., N. Nohria and A. Zaheer, 2000. Strategic networks. Strategic Management Journal, 21(3): 203-216.

Gulati, R., P.R. Lawrence and P. Puranam, 2005. Adaptation in vertical relationships: beyond incentive conflicts. Strategic Management Journal, 26(12): 415-440.

Gyau, A. and A. Spiller, 2009. An integrated model of buyer-seller relationship performance in agribusiness: the partial least squares approach. Journal on Chain and Network Science, 9(1): 25-41.

Hair, J., R. Anderson and W. Black, 1998. Multivariate data analysis. Prentice Hall, Upper Saddle River, NJ, USA.

Håkansson, H. and I. Snehota, 1995. Developing relationships in business networks, Routledge, London, UK.

Handfield, R.B. and C. Bechtel, 2002. The role of trust and relationship structure in improving supply chain responsiveness. Industrial Marketing Management, 31(4): 367-382.

Hanf, J. and C-H. Hanf, 2007. Does food quality management create a competitive advantage? In: Theuvsen, L., A. Spiller, M. Peupert and G. Jahn, (eds.) Quality management in food chains. Wageningen Academic Publishers, Wageningen, the Netherlands, pp. 489-502.

Hanf, J.H. and K. Dautzenberg, 2006. A theoretical framework of chain management. Journal on Chain and Network Science, 6(1): 79-94.

Harland, C.M., R.C. Lamming, J. Zheng and T.E. Johnsen, 2001. A taxonomy of supply networks. Journal of Supply Chain Management, 37(4): 21-27.

Hasanagas, N.D., 2004. Power factor typology through organizational and network analysis - using environmental policy networks as an illustration. Dissertation, Georg-AugustUniversität, Göttingen, Germany.

Henseler, J., C.M. Ringle and R.R. Sinkovics, 2009. The use of partial least squares path modelling in international marketing. Advances in International Marketing, 20: 277-319.

Hingley, M., A. Lindgreen, D. Grant and C. Kane, 2011. Using $4^{\text {th }}$ party logistics management to improve collaboration amongst grocery retailers. Supply Chain Management, 16(5): 316-327. 
Hingley, M.K., 2005. Power to all our friends? Living with imbalance in supplier-retailer relationships. Industrial Marketing Management, 34(8): 848-858.

Jap, S.D. and S. Ganesan, 2000. Control mechanisms and the relationship life cycle: implications for safeguarding specific investments and developing commitment. Journal of Marketing Research, 37(2): 227-245.

Jarillo, J.C., 1988. On strategic networks. Strategic Management Journal, 9(1): 31-41.

Kale, P. and H. Singh, 2007. Building firm capabilities through learning: the role of the alliance learning process in alliance capability and firm-level alliance success. Strategic Management Journal, 28(10): 981-1000.

Kale, P., J.H. Dyer and H. Singh, 2002. Alliance capability, stock market response and long-term alliance success: the role of the alliance function. Strategic Management Journal, 23(8): 747-767.

Kauser, S. and V. Shaw, 2004. The influence of behavioural and organisational characteristics on the success of international strategic alliances. International Marketing Review, 21(1): 17-52.

Kim, B., K. Park and T. Kim, 1999. The perception gap between buyer and suppliers in the semiconductor industry. Supply Chain Management, 4(5): 231-241.

KPMG, 2001. Verticalization in the trade, Published consulting study, KPMG, Cologne, Germany.

Lamming, R.C., T.E. Johnsen, J. Zheng and C.M. Harland, 2000. An initial classification of supply networks. International Journal of Production and Operations Management, 20(6): 675-691.

Leonidou, L.C., M.A. Talias and C.N. Leonidou, 2008. Exercised power as a driver of trust and commitment in cross-border industrial buyer-seller relationships. Industrial Marketing Management, 37(1): 92-103.

Lindgreen, A. and M. Hingley, 2003. The impact of food safety and animal welfare policies on supply chain management: the case of the Tesco meat supply chain. British Food Journal, 105(6): 328-349.

Locke, E.A., 2004. Linking goals to monetary incentives. Academy of Management Executive, 18(4): 130-133.

Madhok, A. and S.B. Tallman, 1998. Resources, transactions, and rents: managing value through interfirm collaborative relationships. Organization Science, 9(3): 326-339.

Medlin, C.J., 2006. Self and collective interest in business relationships. Journal of Business Research, 59(7): 858-865.

Mentzer, J.T., S. Min and Z.G. Zacharia, 2000. The nature of inter-firm partnering in supply chain management. Journal of Retailing, 76(4): 549-568.

Merkens, H., 2000. Auswahlverfahren, Sampling, Fallkonstruktion. In: Flick, U., E. von Kardorff and I. Steinke (eds.) Qualitative Forschung - Ein Handbuch. Rowohlt, Reinbek bei Hamburg, Germany.
Mohr, J. and R. Spekman, 1994. Characteristics of partnership success: partnership attributes, communication behavior, and conflict resolution techniques. Strategic Management Journal, 15(2): 135-152.

Möller, K. and S. Svahn, 2003. Managing strategic nets: a capability perspective. Marketing Theory, 3(2): 201-226.

Möller, K., A. Rajala and S. Svahn, 2005. Strategic business nets their type and management. Journal of Business Research, 58(9): 1274-1284.

Nestlé CT Agriculture, 2006. Nestlé's Sustainable Agriculture Initiatives. Development of milk powder suppliers in Russia. Available at: http://www.nestle.com/Resource.axd?Id=0A7A6E734483-4743-A9A0-47C6C3EB3870.

O'Keefe, M. and A. Fearne, 2002. From commodity marketing to category management: insights from the Waitrose category leadership programme in fresh produce. Supply Chain Management, 7(5): 296-301.

Park, S.H. and G.R. Ungson, 2001. Interfirm rivalry and managerial complexity: a conceptual framework of alliance failure. Organization Science, 12(1): 37-53.

Patton, M.Q., 1990. Qualitative evaluation and research methods. $2^{\text {nd }}$ ed., Sage Publications, Newbury Park, CA, USA.

Paulraj, A. and I.J. Chen, 2005. Strategic supply management and dyadic quality performance: a path analytical model. Journal of Supply Chain Management, 41(3): 4-18.

Payan, J.M. and R.G. McFarland, 2005. Decomposing influence strategies: argument structure and dependence as determinants of the effectiveness of influence strategies in gaining channel member compliance. Journal of Marketing, 69(3): 66-79.

Pitsis, T.S., M. Kornberger and S. Clegg, 2004. The art of managing relationships in interorganizational collaboration. M@n@gement, 7(3): 47-67.

Provan, K.G. and H.B. Milward, 1995. A preliminary theory of network effectiveness: a comparative study of four community mental health systems. Administrative Science Quarterly, 40(1): 1-33.

Provan, K.G. and P. Kenis, 2007. Modes of network governance: structure, management, and effectiveness. Journal of Public Administration Research and Theory, 18(2): 229-252.

Ritter, T., I.F. Wilkinson and W.J. Johnston, 2004. Managing in complex business networks. Industrial Marketing Management, 33(3): 175-183.

Rowley, T.J., D. Behrens and D. Krackhardt, 2000. Redundant governance structures: an analysis of structural and relational embeddedness in the steel and semi-conductor industries. Strategic Management Journal, 21(3): 369-386.

Sarkar, M.B., R. Echambadi, S.T. Cavusgil and P.S. Aulakh, 2001. The influence of complementarity, compatibility, and relationship capital on alliance performance. Journal of the Academy of Marketing Science, 29(4): 358-373. 
Schiefer, G., 2007. Assuring safety and quality along the food chain. In: Nollet, M.L. and F. Toldrá (eds.) Advances in food diagnostics. Blackwell Publishing, Hoboken, NJ, USA, pp.1-10.

Schreiner, M., P. Kale and D. Corsten, 2009. What really is alliance management capability and how does it impact alliance outcomes and success? Strategic Management Journal, 30(13): 1395-1419.

Sparks, L. and B. Wagner, 2003. Retail exchanges; a research agenda. Supply Chain Management, 8(1): 17-25.

Swinnen, J., 2006. The dynamics of vertical coordination in agrofood chains in Europe and Central Asia: case studies. The World Bank, Washington, DC, USA.

Sydow, J. and A. Windeler, 1998. Organizing and evaluating interfirm networks: a structurationist perspective on network processes and effectiveness. Organization Science, 9(3): 265-284.

Theuvsen, L., 2004. Transparency in netchains as an organizational phenomenon: exploring the role of interdependencies. Journal on Chain and Network Science, 4(1): 125-138.

Thompson, J.D., 1967. Organizations in action. McGraw-Hill: New York, NY, USA.

Van de Ven, A.H., 1976. On the nature, formation and maintenance of relations among organizations. Academy of Management Review, 1(4): 24-36.

Viera, J., H. Yoshizaki and L. Ho, 2009. Collaboration intensity in the Brazilian supermarket retail chain. Supply Chain Management, 14(1): 11-21.

Wathne, K.H. and J.B. Heide, 2004. Relationship governance in a supply chain network. Journal of Marketing, 68(1): 73-89.

Winkler, I., 2006. Network governance between individual and collective goals: qualitative evidence from six networks. Journal of Leadership and Organization Studies, 12(3): 119-134.

Wold, H.O., 1982. Soft modeling: the basic design and some extensions. In: Jöreskog, K.G. and H.O. Wold (eds.) Systems under indirect observations, Part II. North-Holland, Amsterdam, the Netherlands, pp.1-54. 


\section{Appendix 1. Operationalisation of the latent variables.}

\author{
Latent construct \\ The level of achievement \\ of network-level goals of \\ network members
}

The level of achievement of firm-level goals of network members

The level of the alignment of interests (cooperation goal of chain management)
Measure (manifest variable)

1. How satisfied are you with the contribution of all your suppliers to the quality of your branded product (e.g. maintenance of product freshness, durability, absence of contaminants, etc.)?

(From 'very dissatisfied' to 'very satisfied')

2. How satisfied are you with the contribution of all your customers to the sales of your branded product?

(From 'very dissatisfied' to 'very satisfied')

3. How satisfied are you with the work of all your suppliers regarding the following aspects: supplies of necessary volumes of product components, proper preservation, traceability of the supplied components, etc.?

(From 'very dissatisfied' to 'very satisfied')

4. How satisfied are you with the work of all your customers regarding the following aspects: product appearance on the shelf, provision of logistics and merchandising services, etc.? (From 'very dissatisfied' to 'very satisfied')

1. To what extent do you think your current suppliers are satisfied with knowledge received from your company?

(From 'very dissatisfied' to 'very satisfied')

2. To what extent do you think your current suppliers are satisfied with the reputation of working together with your company?

(From 'very dissatisfied' to 'very satisfied')

3. To what extent do you think your current suppliers are satisfied with profit generated from cooperation with your company?

(From 'very dissatisfied' to 'very satisfied')

4. To what extent do you think your current customers are satisfied with knowledge received from your company?

(From 'very dissatisfied' to 'very satisfied')

5. To what extent do you think your current customers are satisfied with the reputation of working together with your company?

(From 'very dissatisfied' to 'very satisfied')

6. To what extent do you think your current customers are satisfied with profit generated from cooperation with your company?

(From 'very dissatisfied' to 'very satisfied')

Please indicate your opinion about the following statements:

(From 'strongly disagree' to 'strongly agree')

1. We are certain that the majority of our current suppliers will perform their tasks properly

2. We are certain that the majority of our current customers will perform their tasks properly

3. Most of our suppliers invest enough in quality and technology to be able to meet our requirements

4. Most of our customers invest enough in quality and technology to be able to meet our requirements

5. How satisfied are you with the mutual information exchange with your current suppliers? (From 'very dissatisfied' to 'very satisfied')

6. How satisfied are you with the mutual information exchange with your current customers? (From 'very dissatisfied' to 'very satisfied') 
Latent construct

The level of the alignment of actions

(coordination goal of chain management)

The level of complementarities among network members

The level of coordination capabilities of network members

The level of use of noncoercive power by the focal company
Measure (manifest variable)

1. How satisfied are you with the responsiveness of your suppliers to your requests regarding e.g. process quality, product quality, etc.?

(From 'very dissatisfied' to 'very satisfied')

2. How satisfied are you with the timeliness of delivery of components for your branded product by your current suppliers?

(From 'very dissatisfied' to 'very satisfied')

3. How satisfied are you with the responsiveness of your customers to your requests regarding e.g. product storage, merchandizing, etc.?

(From 'very dissatisfied' to 'very satisfied')

4. How satisfied are you with the timeliness of payments for your branded product by your current customers?

(From 'very dissatisfied' to 'very satisfied')

5. How satisfied are you with the willingness by your current suppliers to perform their operational tasks?

(From 'very dissatisfied' to 'very satisfied')

6. How satisfied are you with the willingness by your current customers to perform their operational tasks?

(From 'very dissatisfied' to 'very satisfied')

Please indicate your opinion about the following statements:

(From 'strongly disagree' to 'strongly agree')

1. The strategies of most of our suppliers correspond to our strategy

2. The cultural norms and values of most of our suppliers correspond to our cultural norms and values

3. The strategies of most of our customers correspond to our strategy

4. The cultural norms and values of most of our customers correspond to our cultural norms and values

Please indicate your opinion about the following statements:

(From 'strongly disagree' to 'strongly agree')

1. Most of our suppliers easily agree if we ask them to perform certain tasks to meet our requirements

2. Most of our customers easily agree if we ask them to perform certain tasks to meet our requirements

3. Most of our suppliers know what they have to do to meet our standards

4. Most of our customers know what they have to do to meet our standards

1. To make your suppliers comply with your standards, how often do you use premiums/bonuses? (From 'very infrequently' to 'very frequently')

2. How often do you provide your suppliers with specific recommendations that help them meet your requirements?

(From 'very infrequently' to 'very frequently')

3. To make your customers comply with your standards, how often do you use premiums/ bonuses?

(From 'very infrequently' to 'very frequently')

4. How often do you provide your customers with specific recommendations that help them meet your requirements?

(From 'very infrequently' to 'very frequently') 


$\begin{array}{ll}\text { Latent construct } & \text { Measure (manifest variable) } \\ \text { The level of trustful } & \text { Please indicate your opinion about the following statements: } \\ \text { relationships among network } & \text { (From 'strongly disagree' to 'strongly agree') } \\ \text { members } & \text { 1. Most of our suppliers believe that our decisions are beneficial for them } \\ & \text { 2. Most of our customers believe that our decisions are beneficial for them } \\ & \text { 3. We always inform our suppliers about our next steps in cooperation } \\ & \text { 4. We always inform our customers about our next steps in cooperation } \\ \text { Please indicate your opinion about the following statements: } \\ \text { (From 'strongly disagree' to 'strongly agree') } \\ \text { 1. We are knowledgeable enough about the decision-making styles of our suppliers } \\ \text { 2. We are knowledgeable enough about the decision-making styles of our suppliers' suppliers } \\ \text { 3. We are knowledgeable enough about the decision-making styles of our customers } \\ \text { 4. We are knowledgeable enough about the decision-making styles of our customers' customers } \\ \text { Please indicate your opinion about the following statements: } \\ \text { (From 'strongly disagree' to 'strongly agree'; reverse coded) } \\ \text { 1. If necessary, we could substitute our suppliers quite easily } \\ \text { 2. If our suppliers wanted to, they could substitute us with another partner quite easily } \\ \text { 3. If necessary, we could substitute our customers quite easily } \\ \text { 4. If our customers wanted to, they could substitute us with another partner quite easily } \\ \text { 5. If necessary, our suppliers easily find common language with each other } \\ \text { 6. If necessary, our customers easily find common language with each other }\end{array}$

